\title{
Violência urbana e capital social em uma cidade no Sul do Brasil: um estudo quantitativo e qualitativo
}

\author{
Eloir Antonio Vial, ${ }^{1}$ José Roque Junges, ${ }^{1}$ Maria Teresa Anselmo Olinto, ${ }^{1}$ \\ Paula Sandrine Machado ${ }^{2}$ e Marcos Pascoal Pattussi ${ }^{1}$
}

Como citar Vial EA, Junges JR, Olinto MTA, Machado PS, Pattussi MP. Violência urbana e capital social em uma cidade no Sul do Brasil: um estudo quantitativo e qualitativo. Rev Panam Salud Publica. 2010; 28(4);289-97.

RESUMO Objetivo. Investigar as relações entre a violência urbana referida e capital social em uma cidade de médio porte no Estado do Rio Grande do Sul, Brasil.

Métodos. O estudo foi realizado com adultos da zona urbana de São Leopoldo. Na etapa quantitativa, um questionário estruturado foi respondido por 1100 pessoas maiores de 20 anos responsáveis pelo domicilio no momento da entrevista. A violência foi avaliada com base nas referências a discussão violenta, roubo ou assalto, caso com drogas e homicídio ocorridos no bairro nos últimos 6 meses. O capital social foi definido a partir do grau relatado de confiança entre vizinhos, apoio social, controle social informal, percepção política e ação social nos bairros avaliados. Na etapa qualitativa, foi realizada uma entrevista semiestruturada com 11 participantes, residentes nos setores com o capital social mais alto e mais baixo.

Resultados. Os residentes em bairros com baixa confiança entre vizinhos relataram uma ocorrência quase 3 vezes maior de homicídios ( $R P=2,82 ;$ IC95\%: 1,67 a 4,74; P> 0,001) e de discussão violenta ( $R P=2,56$; IC95\%: 1,82 a 3,59; $P>0,001)$ em comparação aos moradores de bairros com alta confiança entre vizinhos. As situações relacionadas à violência foram mais enfatizadas em vizinhanças com baixo capital social, nas quais também foi referido o descaso público.

Conclusões. Em vizinhanças com maior capital social, menores percentuais de violência foram referidos. É importante priorizar políticas públicas que promovam o capital social voltado ao bem comum.

Palavras-chave Violência; pesquisa qualitativa; estudos transversais; medicina social; Brasil.

A violência urbana é um fenômeno de abordagem multifacetada, intersetorial e interdisciplinar. Pode ser analisada em termos de aspectos que dizem respeito

\footnotetext{
1 Universidade do Vale do Rio dos Sinos (UNISINOS), Programa de Pós-Graduação em Saúde Coletiva, São Leopoldo (RS), Brasil. Correspondência: roquejunges@hotmail.com

2 Universidade Federal do Rio Grande do Sul (UFRGS), Departamento de Psicologia Social e Institucional, Porto Alegre (RS), Brasil.
}

a indivíduos, grupos, classes e instituições, que em suas relações empregam diferentes métodos e meios de coerção e aniquilamento da pessoa (1-4).

Na década de 1990, a Organização Mundial da Saúde (OMS) e a Organização Pan-Americana da Saúde (OPAS) promoveram atividades e importantes políticas públicas de saúde relacionadas à violência. A OPAS chamou atenção, em 1994, para o número de vítimas e para a magnitude de sequelas que a violência produz. Declarou que a mesma adquiriu um caráter endêmico e se converteu em um problema de saúde pública em muitos países (5). Em 1996, a OMS adotou a Resolução WHA49.25, que declarou a violência como o maior e mais crescente problema de saúde pública no mundo (6). No relatório mundial sobre violência e saúde publicado em 2002, estimou-se que o número de 
mortes causadas por atos violentos no mundo, no ano de 2000, foi de 1,6 bilhão, ou cerca de 29 mortes a cada 100000 habitantes (4).

Dados disponibilizados em 2002 pela OMS (4) mostram que as taxas de cada tipo de violência variam entre países, regiões e cidades, assim como variam também dentro dessas unidades geográficas. Nas Américas, a cada ano ocorrem cerca de 20 homicídios em cada 100000 habitantes. De acordo com o mesmo relatório, a América Latina apresenta a taxa de homicídios anual mais elevada entre jovens de 10 a 29 anos: 36,5 por 100000 habitantes. No Brasil, entre 1991 e 2000, houve uma elevação de cerca de $48 \%$ na taxa de mortalidade por homicídios na população jovem (15 a 24 anos), enquanto na população total o crescimento foi de quase $30 \%$. No Estado do Rio Grande do Sul, entre 1990 e 2000, considerando-se as mortes por causas externas, os homicídios representaram cerca de $22,9 \%$ (7).

A magnitude e o crescimento nas taxas de mortalidade por homicídio têm forte impacto social, envolvendo o poder público e a sociedade civil (4). De uma perspectiva pública, o Estado é diretamente responsável pela construção de políticas de segurança pública para e com a comunidade. De uma perspectiva social, a sociedade civil, com suas organizações formais e informais, pode contribuir para melhorar a qualidade de vida comunitária $(2,3,8)$.

As organizações, as redes de relações entre organismos e os grupos formais e informais de pessoas são bens inalienáveis da comunidade que favorecem e fortalecem a cidadania e a participação política, com impacto direto na prevenção do crime. Essas redes de relação têm sido entendidas como capital social. Coleman (9) define capital social como a reciprocidade nas relações sociais; para Putnam $(10,11)$ o capital social é o conjunto de normas e redes da estrutura social que habilitam os participantes a agir juntos e mais efetivamente na busca de objetivos comuns. O conceito envolve, portanto, a cultura cívica, a confiança entre os membros da comunidade, o envolvimento nas questões comunitárias e a boa relação entre vizinhos. Diz respeito a normas e redes que favorecem a ação coletiva com vistas ao bem comum $(9,10$, 12). As principais ações do capital social incluem: encorajar a confiança social, preservar os bens públicos, facilitar a co- operação mútua e melhorar o fluxo de informações $(13,14)$.

Apesar da possibilidade de impactos negativos do capital social (15-17), a literatura sugere que as sociedades com altos níveis de capital social são mais igualitárias, sendo as pessoas mais envolvidas na vida pública e mais solidárias. Essas pessoas vivem mais e são menos violentas (18-20). Diferentes estudos têm demonstrado que maiores taxas de diversos indicadores de violência estão consistentemente associadas a menor capital social, seja em contextos mais amplos (estados) ou mais restritos (bairros) (18-23).

Nesse sentido, o objetivo do presente estudo foi investigar as relações entre violência urbana referida e capital social em um bairro de uma cidade de médio porte do Sul do Brasil.

\section{MATERIAIS E MÉTODOS}

A presente pesquisa integra as metodologias quantitativa e qualitativa para a coleta e a análise dos dados. Na primeira fase, realizou-se um estudo epidemiológico transversal, com uma amostra representativa de 1100 pessoas com 18 ou mais anos de idade. Na segunda fase, realizou-se um estudo qualitativo com 11 participantes da primeira fase. A fase qualitativa buscou aprofundar os dados quantitativos $(24,25)$. O objetivo dessa estratégia foi explicar a extensão ou magnitude (quantitativo) e compreender a intensidade (qualitativo) dos processos sociais (26). O estudo por integração de métodos é sustentado por três pilares: o respeito entre os distintos campos, a ampliação da visão de método e a capacidade de diálogo entre pesquisadores (27).

Os participantes residiam na zona urbana de São Leopoldo, Rio Grande do Sul. Em 2005, São Leopoldo possuía uma população de 209611 habitantes, com taxa de crescimento anual de $1,72 \%$, densidade populacional de 2 048,78 hab/ $\mathrm{km}^{2}$, taxa de analfabetismo de $4,78 \%$, expectativa de vida ao nascer no ano de 2000 de 69 anos e coeficiente de mortalidade infantil em 2004 de 10,16 por 1000 nascidos vivos. Em 2005, a Cidade tinha 100 praças, 2062 ruas, 70 avenidas, 120 travessas e 53498 domicílios. Os dados indicam ainda a presença de 23 bancos, 406 indústrias, 2008 estabelecimentos comerciais, 3999 prestadores de serviços, 5780 autônomos e 114 entidades sem fins lucrativos (28). De acordo com dados do Instituto Brasileiro de Geografia e Estatística (IBGE), as médias de renda e de anos de estudo dos chefes de família eram de $\mathrm{R} \$ 955$ (desvio padrão, $\mathrm{DP}=586)$ e 8 anos $(\mathrm{DP}=3)$, respectivamente, nos setores censitários estudados. O número médio de residentes por setor foi igual a $746(\mathrm{DP}=358)(29)$.

São Leopoldo pertence à Região Metropolitana de Porto Alegre, capital do Estado, que reúne 11 cidades e mais de 3 milhões de habitantes. Em relação aos serviços públicos de saúde, existem um hospital geral, seis centros de saúde, 20 unidades de atenção básica, um serviço de atendimento especializado para doenças sexualmente transmissíveis e Aids, um Centro de Vigilância em Saúde, uma Farmácia Municipal, uma Farmácia Popular do Brasil, dois centros de atenção psicossocial e um laboratório para análises clínicas. Quanto aos serviços de segurança pública, possui sete postos da Brigada Militar, cinco delegacias de polícia civil e um presídio regional (28). Deve-se ressaltar que o Município de São Leopoldo, dentre os 5564 municípios brasileiros, encontra-se entre os 200 municípios mais violentos do país (30). Considerando os 496 municípios do Estado, encontra-se entre os 10 mais violentos (31).

\section{Abordagem quantitativa}

A abordagem quantitativa envolveu um estudo com delineamento transversal de base populacional, com entrevistas estruturadas na forma de um questionário padronizado e pré-testado. $\mathrm{O}$ tamanho da amostra foi calculado com base em um estudo piloto que utilizou o método para proporções com aleatorização de conglomerados e o método do desfecho de autopercepção em saúde.

O tamanho da amostra foi calculado para obter $85 \%$ de poder $(1-\beta=0,85)$ para detectar uma diferença de $7 \%$ na prevalência de autopercepção de saúde ruim entre áreas com alto e baixo capital social, com nível de confiança de $95 \%$. Para esse cálculo, foram utilizados 35 domicílios por setor. Estimou-se serem necessários 1260 domicílios em 36 setores. Para compensar possíveis perdas e para controle de possíveis fatores de confusão, a amostra foi aumentada em $20 \%$ no número de domicílios e em $10 \%$ no número de setores. Portanto, o cálculo final previu uma amostra de 1512 domicílios em 40 setores censitários (em torno 
de 38 domicílios por setor). Em cada conglomerado (setor censitário), foi sorteado o quarteirão para iniciar a pesquisa, e todos os domicílios foram visitados até completar o número requerido de $38 \mathrm{em}$ cada conglomerado.

Foram realizadas 1100 entrevistas em 38 setores, o que representou $72 \%$ do cálculo inicial. A coleta de dados foi interrompida em nove setores censitários e não foi realizada em dois devido à falta de recursos financeiros por parte do projeto. Nesses 11 setores, foram entrevistadas 127 pessoas de um total previsto de 420. Assim, os principais motivos das perdas foram a falta de recursos financeiros do projeto (14\%), a existência de domicílios não habitados ou comércio $(8 \%)$, as recusas $(4 \%)$ e ausência dos moradores $(2 \%)$.

A coleta de dados foi realizada por 50 entrevistadores, alunos da graduação da Universidade do Rio dos Sinos (UNISINOS), os quais foram devidamente treinados e padronizados. Foram entrevistados os responsáveis pelos domicílios, indivíduos maiores de 18 anos presentes no domicílio e responsáveis pelo mesmo no momento da entrevista. No caso da ausência de um responsável, foram realizadas três visitas de retorno.

Violência referida (desfecho do estudo) foi dicotomizada ("sim" ou "não") e avaliada pela percepção dos entrevistados quanto à ocorrência na vizinhança, nos últimos 6 meses, de "discussão violenta entre vizinhos, roubo ou assalto, caso relacionado com drogas e homicídio". Tais perguntas são originárias do clássico estudo de Sampson et al. sobre violência e eficácia coletiva em bairros de Chicago (18).

Quanto ao capital social, foi avaliado através de 23 perguntas acerca de 5 dimensões, com base na literatura sobre $o$ tema $(18,32-34)$ :

- confiança social (cinco perguntas): perguntou-se se o entrevistado concordava com afirmações sobre os vizinhos se ajudarem, a vizinhança ser amigável, haver união entre vizinhos e os vizinhos compartilharem os mesmos valores (18).

- Apoio social (quatro perguntas): perguntou-se se o entrevistado se sentiria à vontade se tivesse que contar com a ajuda de um vizinho para: pegar um remédio na farmácia, conversar sobre um problema pessoal, tomar conta dos filhos e pedir empres- tada uma pequena quantidade de dinheiro (32).

- Controle social informal (cinco perguntas): perguntou-se até que ponto os entrevistados concordavam com afirmações a respeito da possibilidade de contar com vizinhos para intervir em casos de crianças/adolescentes matando aula (faltando aula sem conhecimento dos responsáveis), pichando ou destruindo bens públicos e desrespeitando pessoas idosas, brigas entre vizinhos; e se concordavam que os vizinhos agiriam no caso do fechamento do posto de saúde da comunidade (18).

- Percepção política (quatro perguntas): perguntou-se se os entrevistados concordavam com afirmações como: governantes não ligam para os cidadãos; não estão interessados no que os cidadãos pensam; os partidos políticos só estão interessados nos votos; os políticos eleitos perdem o contato com as pessoas após a eleição (33).

- Ação social (cinco perguntas): perguntou-se sobre a frequência com que os entrevistados conversavam sobre problemas da vizinhança; participaram de abaixo-assinado; se reuniam; faziam contato com os governantes; e contatavam a mídia para resolução dos problemas locais (34).

As resposta foram na forma de escala de Likert. No caso das dimensões confiança social, controle social informal e percepção política, as categorias foram: concordo totalmente, concordo, não concordo nem discordo, discordo, discordo totalmente. As categorias de resposta para apoio social foram: não pediria ajuda, muito desconfortável, um pouco desconfortável, um pouco à vontade e muito à vontade. Para ação social, as categorias foram: nunca fiz isso, há mais de 12 meses, nos últimos 12 meses, nos últimos 6 meses e nos últimos 3 meses. Para avaliar essas dimensões, os escores das respostas que as compunham foram somados, criando-se uma variável categórica ordinal, classificada em uma entre três categorias: nível baixo (= zero; $25 \%$ escores menores), nível moderado $(=1$; $50 \%$ escores intermediários) ou nível alto ( $=2 ; 25 \%$ escores elevados).

Para gerar um escore de capital social para cada um dos entrevistados, os escores das cinco variáveis ordinais (representando cada construto) obtidos a partir de cada entrevista específica foram so- mados. Como havia cinco perguntas, cujas respostas poderiam ser categorizadas como zero, 1 ou 2, criou-se um escore de 0 a 10, sendo 10 igual ao maior capital social. Com base nesse escore, o capital social foi classificado como baixo ( 0 a 3 pontos), moderado (4 a 6 ) ou alto ( $\geq 7$ pontos).

O capital social da área foi definido a partir da média aritmética dos escores individuais em cada um dos 38 setores censitários. A distribuição das médias do escore global do capital social individual em cada um setores foi utilizada na criação do capital social da área. Similarmente à criação do escore para cada dimensão individual, criou-se uma variável categórica ordinal baseada nos quartis da distribuição. Assim sendo, 7 setores foram classificados como baixo, 10 como alto e 21 como moderado capital social. Com vistas a uma maior compatibilização entre as abordagens quanti e qualitativa, a categoria moderado para todas as variáveis representado capital social não foi apresentada.

$\mathrm{Na}$ análise dos dados foi empregada a regressão de Poisson com variância robusta (35) e o controle para efeito de delineamento, de modo a obter razão de prevalência (RP) e o IC95\%.

\section{Abordagem qualitativa}

O trabalho de campo da etapa qualitativa foi realizado nos anos de 2008 e 2009. Onze pessoas foram selecionadas a partir da coleta quantitativa. Essas pessoas responderam, no domicílio, entrevistas semiestruturadas, utilizando-se um roteiro norteador do tema. As entrevistas tiveram em média 1 hora de duração. Foram gravadas em áudio e posteriormente transcritas integralmente.

Para seleção dos participantes foram utilizados o local com o maior e o com menor capital social. Desses locais selecionou-se uma amostra por conveniência composta por 11 pessoas (cinco ou seis sujeitos de cada um dos dois locais selecionados), observando-se uma relativa distribuição por sexo e idade nos grupos etários (18 a 29 anos; 30 a 59 anos; 60 anos ou mais).

Após a seleção, foi realizado contato telefônico com os candidatos e agendada a entrevista. Para manter o anonimato dos participantes, foram atribuídos nomes fictícios, seguidos de um número que corresponde à idade informada no momento do estudo. Além disso, foram 
atribuídos nomes com a inicial "A" para as pessoas residentes no setor de alto capital social, e com a inicial " $\mathrm{B}$ " àquelas do setor de baixo capital social. No local de maior capital social, foram entrevistados: Amanda 21, Andréa 22, Adriana 32, Ana 44 e Antônio 55. No local de menor capital social, foram entrevistados Bruna 20, Beto 23, Bianca 49, Brenda 49, Breno 50 e Bernardo 70. Para a análise qualitativa foi utilizado o método de análise de conteúdo, segundo Bardin (36) e Minayo (37), de forma a apreender as percepções de capital social e violência urbana.

O protocolo de pesquisa foi aprovado pelo Comitê de Ética em Pesquisas da UNISINOS, tendo cumprido os requisitos da Resolução 196/96 do Conselho Nacional de Saúde.

\section{RESULTADOS}

\section{Dados quantitativos}

Entre as 1100 pessoas da amostra, seis não responderam as questões sobre a ocorrência de discussão violenta, roubo ou assalto e fato relacionado com drogas e sete não responderam sobre homicídio. A tabela 1 resume os dados sociodemográficos dos 1100 participantes e mostra a distribuição dos participantes conforme as categorias de violência referida.

As prevalências de violência referida nos últimos 6 meses foram: discussão violenta $(17,1 \%$; IC95\%: 15 a 19,4), roubo ou assalto (42,8\%; IC95\%: 39,9 a 45,7), caso com drogas (32,4\%; IC95\%: 29,7 a $35,2)$ e homicídio (8,4\%; IC95\%: 6,9 a 10,2) (tabela 1).

A tabela 2 mostra a relação entre capital social e violência urbana referida. Maiores prevalências de todos os indicadores de violência foram encontradas nos locais com baixa confiança e menor controle social informal na vizinhança. Os locais cujos residentes relataram baixa confiança entre vizinhos possuíam cerca de 3 vezes maior prevalência de discussão violenta quando comparados aos setores com alta confiança.

As pessoas que relataram baixo controle social informal possuíam uma prevalência duas vezes maior para homicídios e para discussão violenta quando comparadas com aquelas que relataram alto controle (tabela 2). Do mesmo modo, aqueles que relataram baixo apoio social mencionaram uma ocorrência duas vezes maior de discussões violentas entre vizinhos $(\mathrm{RP}=2,14$; IC95\%: 1,10 a

TABELA 1. Distribuição da amostra total e dos setores com alto e baixo capital social de acordo com aspectos demográficos, socioeconômicos, construtos do capital social e violência urbana referida, São Leopoldo (RS), Brasil, 2007

\begin{tabular}{|c|c|c|c|c|c|c|}
\hline \multirow[b]{2}{*}{ Variável } & \multicolumn{2}{|c|}{ Total } & \multicolumn{2}{|c|}{$\begin{array}{l}\text { Áreas com alto } \\
\text { capital social }\end{array}$} & \multicolumn{2}{|c|}{$\begin{array}{c}\text { Áreas com baixo } \\
\text { capital social }\end{array}$} \\
\hline & No. & $\%$ & No. & $\%$ & No. & $\%$ \\
\hline$n$ & 1100 & 100 & 274 & 24,9 & 272 & 24,7 \\
\hline \multicolumn{7}{|l|}{ Sexo } \\
\hline Masculino & 310 & 28,2 & 70 & 25,5 & 76 & 25,5 \\
\hline Feminino & 790 & 71,8 & 204 & 74,5 & 196 & 74,5 \\
\hline \multicolumn{7}{|l|}{ Idade (anos) } \\
\hline 60 e mais (idoso) & 196 & 17,8 & 47 & 17,2 & 56 & 20,6 \\
\hline 30 a 59 (adulto) & 657 & 59,7 & 171 & 62,4 & 148 & 50,4 \\
\hline 18 a 29 (jovem) & 247 & 22,5 & 56 & 20,4 & 68 & 25,0 \\
\hline \multicolumn{7}{|l|}{ Cor da pele observada } \\
\hline Branca & 922 & 84,0 & 227 & 82,2 & 225 & 82,7 \\
\hline Não branca & 176 & 16,0 & 47 & 17,2 & 47 & 17,3 \\
\hline \multicolumn{7}{|l|}{ Estado civil } \\
\hline Em união & 615 & 55,9 & 148 & 54,0 & 142 & 52,2 \\
\hline Solteiro & 267 & 24,3 & 70 & 25,5 & 72 & 26,5 \\
\hline Outro & 218 & 19,8 & 56 & 20,4 & 58 & 21,3 \\
\hline \multicolumn{7}{|c|}{ Renda familiar (salários mínimos) } \\
\hline$>9$ & 262 & 24,4 & 61 & 22,2 & 44 & 16,1 \\
\hline 3 a 9 & 535 & 51,4 & 129 & 47,8 & 163 & 59,5 \\
\hline$<3$ & 234 & 21,3 & 66 & 24,4 & 64 & 23,4 \\
\hline \multicolumn{7}{|l|}{ Escolaridade (anos) } \\
\hline 11 e mais & 388 & 36,4 & 67 & 26 & 89 & 33,5 \\
\hline 5 a 10 & 475 & 44,5 & 128 & 49,6 & 133 & 50,0 \\
\hline 0 a 4 & 204 & 19,1 & 63 & 24,4 & 44 & 16,5 \\
\hline \multicolumn{7}{|c|}{ Classe econômica (ABEP)a } \\
\hline$A-B$ & 336 & 31,6 & 76 & 29,5 & 73 & 27,5 \\
\hline C & 489 & 45,9 & 125 & 48,4 & 120 & 45,3 \\
\hline D-E & 240 & 22,5 & 57 & 22,1 & 72 & 27,2 \\
\hline \multicolumn{7}{|c|}{ Confiança entre vizinhos ${ }^{b}$} \\
\hline Alta & 387 & 35,4 & 123 & 45,1 & 69 & 25,7 \\
\hline Baixa & 255 & 23,3 & 34 & 12,5 & 83 & 31,0 \\
\hline \multicolumn{7}{|c|}{ Apoio social entre vizinhos ${ }^{b}$} \\
\hline Alto & 252 & 23,1 & 89 & 32,6 & 43 & 16,1 \\
\hline Baixo & 255 & 23,4 & 35 & 12,8 & 97 & 36,3 \\
\hline \multicolumn{7}{|c|}{ Controle social informal no bairrob } \\
\hline Alto & 160 & 14,6 & 68 & 24,9 & 12 & 4,5 \\
\hline Baixo & 264 & 24,2 & 38 & 13,9 & 97 & 36,2 \\
\hline \multicolumn{7}{|l|}{ Percepção políticab } \\
\hline Alta & 245 & 22,4 & 67 & 24,5 & 55 & 20,5 \\
\hline & 240 & 21,9 & 68 & 24,9 & 42 & 15,7 \\
\hline \multicolumn{7}{|l|}{ Ação social ${ }^{b}$} \\
\hline Alta & 270 & 24,7 & 93 & 34,1 & 45 & 16,8 \\
\hline Baixa & 332 & 30,4 & 59 & 21,6 & 102 & 38,1 \\
\hline Discussão violenta & & & & & & \\
\hline Não & 907 & 82,9 & 237 & 86,8 & 210 & 78,4 \\
\hline Sim & 187 & 17,1 & 36 & 13,2 & 58 & 21,6 \\
\hline Roubo ou assalto & & & & & & \\
\hline Não & 626 & 57,2 & 163 & 59,7 & 137 & 51,1 \\
\hline Sim & 468 & 42,8 & 110 & 40,3 & 131 & 48,9 \\
\hline Caso com drogas & & & & & & \\
\hline Não & 739 & 67,6 & 192 & 70,3 & 179 & 66,8 \\
\hline Sim & 354 & 32,4 & 81 & 29,7 & 89 & 33,2 \\
\hline Homicídio & & & & & & \\
\hline Não & 1002 & 91,6 & 254 & 93,0 & 241 & 89,9 \\
\hline Sim & 92 & 8,4 & 19 & 7,0 & 27 & 10,1 \\
\hline Capital social individu & & & & & & \\
\hline Alto & 263 & 24,2 & 101 & 37 & 43 & 16,2 \\
\hline Baixo & 246 & 22,6 & 25 & 9,2 & 97 & 36,5 \\
\hline
\end{tabular}

${ }^{a} \mathrm{ABEP}=$ Associação Brasileira de Estudos Populacionais.

b O número de casos é menor nestas variáveis porque os dados referentes à categoria "moderado" não foram apresentados.

4,74; $P<0,001$ ) (tabela 2). Entretanto, no sentido contrário, os indivíduos que consideraram sua área de residência como tendo baixa ação social referiam menor ocorrência de violência em todos os indicadores. A percepção política não esteve associada a nenhum dos indicadores (tabela 2). 
TABELA 2. Distribuição das variáveis de violência referida nos últimos 6 meses de acordo com construtos e com capital social individual e da área, São Leopoldo (RS), Brasil, 2007a

\begin{tabular}{|c|c|c|c|c|c|c|c|c|}
\hline \multirow[b]{2}{*}{ Construto } & \multicolumn{8}{|c|}{ Violência referida } \\
\hline & $\begin{array}{c}\text { Discussão } \\
\text { violenta } \\
(\%)\end{array}$ & $\begin{array}{l}\mathrm{RP}(\mathrm{IC} 95 \%)^{\mathrm{b}} \\
\text { Valor } P\end{array}$ & $\begin{array}{l}\text { Roubo ou } \\
\text { assalto } \\
(\%)\end{array}$ & $\begin{array}{l}\mathrm{RP}(\mathrm{IC} 95 \%)^{\mathrm{b}} \\
\text { Valor } P\end{array}$ & $\begin{array}{l}\text { Caso com } \\
\text { drogas } \\
(\%)\end{array}$ & $\begin{array}{l}\mathrm{RP}(\mathrm{IC} 95 \%)^{\mathrm{b}} \\
\text { Valor } P\end{array}$ & $\begin{array}{l}\text { Homicídio } \\
(\%)\end{array}$ & $\begin{array}{l}\mathrm{RP}(\mathrm{IC} 95 \%)^{\mathrm{b}} \\
\text { Valor } P\end{array}$ \\
\hline \multicolumn{9}{|c|}{ Confiança entre vizinhos } \\
\hline Alta & 11,4 & 1 & 34,6 & 1 & 24,0 & 1 & 5,2 & 1 \\
\hline Baixa & 29,1 & $\begin{array}{c}2,56(1,82 \text { a } 3,59) \\
P<0,001\end{array}$ & 55,9 & $\begin{array}{c}1,61(1,35 \text { a } 1,92) \\
P<0,001\end{array}$ & 45,7 & $\begin{array}{c}1,90(1,52 \text { a } 2,37) \\
P<0,001\end{array}$ & 14,6 & $\begin{array}{c}2,82(1,67 \text { a } 4,74) \\
P<0,001\end{array}$ \\
\hline \multicolumn{9}{|c|}{ Apoio social entre vizinhos } \\
\hline Alto & 14,3 & 1 & 39,7 & 1 & 27,1 & 1 & 4,8 & 1 \\
\hline Baixo & 20,0 & $\begin{array}{c}1,40(0,95 \text { a } 2,07) \\
P=0,087\end{array}$ & 45,1 & $\begin{array}{c}1,14(0,93 \text { a } 1,39) \\
P=0,218\end{array}$ & 36,0 & $\begin{array}{c}1,33(1,03 \text { a } 1,73) \\
P=0,030\end{array}$ & 10,2 & $\begin{array}{c}2,14(1,10 \text { a } 4,15) \\
P=0,019\end{array}$ \\
\hline \multicolumn{9}{|c|}{$\begin{array}{l}\text { Controle social informal na } \\
\text { vizinhança }\end{array}$} \\
\hline Alto & 11,3 & 1 & 36,9 & 1 & 26,4 & 1 & 6,3 & 1 \\
\hline Baixo & 25,4 & $\begin{array}{c}2,25(1,40 \text { a } 3,65) \\
P<0,001\end{array}$ & 47,0 & $\begin{array}{c}1,27(1,00 \text { a } 1,62) \\
P=0,042\end{array}$ & 39,4 & $\begin{array}{c}1,49(1,10 \text { a } 2,01) \\
P=0,003\end{array}$ & 13,6 & $\begin{array}{c}2,18(1,11 \text { a } 4,27) \\
P=0,004\end{array}$ \\
\hline \multicolumn{9}{|l|}{ Percepção política } \\
\hline Alta & 15,5 & 1 & 42,5 & 1 & 34,3 & 1 & 10,2 & 1 \\
\hline Baixa & 15,0 & $\begin{array}{c}0,97(0,63 \text { a } 1,47) \\
P=0,885\end{array}$ & 41,3 & $\begin{array}{c}0,97(0,79 \text { a } 1,20) \\
P=0,792\end{array}$ & 36,0 & $\begin{array}{c}1,05(0,82 \text { a } 1,34) \\
P=0,708\end{array}$ & 8,8 & $\begin{array}{c}0,85(0,49 \text { a } 1,49) \\
P=0,579\end{array}$ \\
\hline \multicolumn{9}{|l|}{ Ação social } \\
\hline Alta & 23,0 & 1 & 51,5 & 1 & 47,4 & 1 & 11,5 & 1 \\
\hline Baixa & 14,2 & $\begin{array}{c}0,61(0,44 \text { a } 0,86) \\
P=0,007\end{array}$ & 36,8 & $\begin{array}{c}0,71(0,59 \text { a } 0,86) \\
P<0,001\end{array}$ & 23,9 & $\begin{array}{c}0,50(0,40 \text { a } 0,63) \\
P<0,001\end{array}$ & 7,23 & $\begin{array}{c}0,63(0,38 \text { a } 1,05) \\
P=0,084\end{array}$ \\
\hline \multicolumn{9}{|c|}{ Capital social individual } \\
\hline Alto & 13,7 & 1 & 39,9 & 1 & 30,4 & 1 & 6,8 & 1 \\
\hline Baixo & 23,2 & $\begin{array}{c}1,69(1,16 \text { a } 2,71) \\
P=0,027\end{array}$ & 45,1 & $\begin{array}{c}1,13(0,89 \text { a } 1,44) \\
P=0,306\end{array}$ & 36,2 & $\begin{array}{c}1,19(0,93 \text { a } 1,51) \\
P=0,153\end{array}$ & 11,8 & $\begin{array}{c}1,72(0,93 \text { a } 3,18) \\
P=0,090\end{array}$ \\
\hline \multicolumn{9}{|l|}{ Capital social de área } \\
\hline Alto & 13,2 & 1 & 40,3 & 1 & 29,7 & 1 & 7,0 & 1 \\
\hline Baixo & 21,6 & $\begin{array}{c}1,64(0,82 \text { a } 3,27) \\
P=0,145\end{array}$ & 48,9 & $\begin{array}{c}1,21(0,80 \text { a } 1,82) \\
P=0,330\end{array}$ & 33,2 & $\begin{array}{c}1,11(0,77 \text { a } 1,63) \\
P=0,547\end{array}$ & 10,1 & $\begin{array}{c}1,45(0,44 \text { a } 4,75) \\
P=0,090\end{array}$ \\
\hline
\end{tabular}

${ }^{a} n=1$ 100. Não são apresentados dados da categoria moderado.

${ }^{\text {b }} \mathrm{RP}(\mathrm{IC} 95 \%)=$ razão de prevalências e intervalo de confiança de $95 \%$.

Com relação aos escores globais, embora com achados não significativos, foi constatada uma tendência de áreas e indivíduos indicando baixo capital social possuírem maiores relatos de discussão violenta entre vizinhos e de homicídios (tabela 2).

\section{Resultados qualitativos}

Entre as 11 pessoas selecionadas, cinco pertenciam ao local com maior capital social e seis ao local com menor capital social (tabela 3).

Os resultados qualitativos foram agrupados por semelhança e também divergências de informações. Por exemplo, a confiança e o controle social informal ambos estabeleceram relações de proximidade; por isso, os dois construtos puderam ser analisados tanto separadamente quanto em conjunto. Os participantes demonstraram haver uma aproximação entre cuidar do bem material privado, como a casa, por exemplo, com o sentido de controle social informal.

TABELA 3. Características dos 11 participantes da fase qualitativa da pesquisa sobre violência urbana e capital social, São Leopoldo (RS), Brasil, 2009

\begin{tabular}{|c|c|c|c|c|c|c|}
\hline Sujeito ${ }^{a}$ & $\begin{array}{l}\text { Idade } \\
\text { (anos) }\end{array}$ & Sexo & $\begin{array}{l}\text { Cor da } \\
\text { pele } \\
\text { referida }\end{array}$ & Estado civil & Escolaridade referida & $\begin{array}{c}\text { Reside } \\
\text { no endereço } \\
\text { (anos) }\end{array}$ \\
\hline Amanda & 21 & Feminino & Morena & Casada & Médio completo & 21 \\
\hline Ágatha & 22 & Feminino & Branca & Solteira & Fundamental completo & 8 \\
\hline Adriana & 32 & Feminino & Branca & União estável & Superior incompleto & 31 \\
\hline Ana & 44 & Feminino & Morena & União estável & Fundamental incompleto & 17 \\
\hline Augusto & 55 & Masculino & Branca & Casado & Fundamental completo & 17 \\
\hline Beatriz & 20 & Feminino & Branca & Solteira & Médio completo & 20 \\
\hline Baltazar & 23 & Masculino & Morena & Solteiro & Fundamental incompleto & 19 \\
\hline Berenice & 49 & Feminino & Branca & Separada & Médio completo & 49 \\
\hline Bárbara & 49 & Feminino & Branca & Casada & Fundamental incompleto & 21 \\
\hline Breno & 50 & Masculino & Branca & Casado & Fundamental incompleto & 6 \\
\hline Bernardo & 70 & Masculino & Branca & Casado & Fundamental incompleto & 35 \\
\hline
\end{tabular}

a Nomes iniciados com a letra A indicam participantes de zonas com alto capital social; nomes iniciados com a letra B indicam participantes de zonas com baixo capital social.

Esse controle, por sua vez, foi entendido também como atitude de confiança. Ágatha 22 disse que "aqui um sai o outro toma conta. Aqui sim, aqui está bom de morar. Quando a gente sai a gente pode ter confiança que vai cuidar". Já Bernardo 70 falou dessa situação como uma atitude superficial, onde "às vezes um sai o outro dá uma reparada", e ressaltou a falta de resultado: "o senhor vê os muros ali, tudo riscado. Ali do meu vizinho pintou esses dias, riscaram tudo". Embora o controle social tenha sido identificado nos dois setores, existem 
descontinuidades entre as idéias de "cuidar" e de "dar uma reparada".

O construto "apoio social" significa o apoio oferecido ou recebido, tanto individual quanto no grupo. É um processo recíproco que mostra que as pessoas necessitam umas das outras. De um modo geral, os sujeitos afirmaram que acontecem efeitos benéficos à pessoa e à comunidade decorrentes desse tipo de apoio. Para Ana 44, esse apoio tem a ver com as organizações da comunidade. Segundo ela, "existe o clube de mães, o posto de saúde, o colégio. E conheço bastante mulheres que fazem curso de crochê, fazem curso de costura no Parque dos Trabalhadores".

Quanto à política, houve diferentes percepções entre os participantes, inclusive do mesmo setor. Essas percepções estão associadas com o fazer ações públicas na comunidade. Como disse Amanda 21, "eles podiam fazer mais. Falar e fazer e não só falar. Toda vez que eles falam não fazem. Não sai nunca do papel. Acho que eles podiam vir mais nas vilas. Fazer mais as coisas nas vilas também". E Ágatha 22, "esse [governo] aqui está melhor. Pelo menos o posto aqui agora não fecha ao meio dia. Tem médico sempre. $\mathrm{E}$ aquele lá não fecha mais no final de semana" [são 2 unidades de saúde].

Segundo Szreter e Woolcock (13), o capital social produz políticas públicas efetivas na comunidade, o que é exemplificado pela fala de Ágatha 22. Por outro lado, os autores reconhecem que nem todas as relações são geradoras do bem comum, como no exemplo de Amanda 21. Existem situações em que o poder é utilizado para controlar ou dominar os mais "fracos". Isso pode ocorrer tanto no nível do poder público quanto da sociedade civil, como, por exemplo, quando há residentes violentos em uma comunidade. Berenice 49 exemplifica uma questão que envolve o poder público e a fragilidade civil na área de residência, onde "moradores daqui, qualquer denúncia que fizer não resolvem [frente ao público], porque eles [a polícia, serviço público] levam o indivíduo [preso] e quando chega a noite ... está de volta. Aí, tu acaba o que? Arrumando um problema pra ti, porque se descobre que foi tu, a polícia não vai te defender. Então, a comunidade aqui nem se envolve". Beatriz 20 tem uma percepção política semelhante, pois, "o governo olha só para um lado da cidade. Aqui fica sempre esquecido. Aqui parece o canto dos esquecidos ... não passa uma viatura, não tem projeto social nenhum, aqui não tem nada".

Quanto ao construto ação social, é exemplificado por Amanda 21 através das organizações existentes em sua comunidade: "escola tem ... CTG [Centro de Tradições Gaúchas] ... posto de saúde ... Igreja ... escolinha para as crianças mais pobres ... CLJ, ONDA [grupos de jovens cristãos]. Tem Assembleia de Deus, Testemunha de Jeová, Adventista. E escola aberta sábado e domingo. Estão deixando a gente mais tranquila. Todo mundo fica ali aonde todos vão se encontrar, vão se conhecer mais também".

Além disso, no setor de maior capital social as organizações parecem ser mais presentes na vida das pessoas, cumprem um papel social importante, são percebidas como atuantes e importantes em diversas esferas, como educação e cidadania, como citou anteriormente Amanda 21 e foi reforçado por Adriana 32: "é aonde as crianças vão [CTG]. Daí eles aprendem. Até a gente ensina uma educação, mas lá eles aprendem outro tipo. Lá tu tens que aprender algo mais, para ti melhorar".

Já no setor de menor capital social, ainda que as organizações possam existir concretamente, são percebidas como estando mais no plano do desejável do que no da realidade, que pode estar relacionado com a inserção das mesmas na vida das pessoas. Como referiu Beatriz 20: "esses dias a gente estava conversando. Tivesse uns grupos, uma coisa assim. E não tem um movimento tipo uma associação. Eu queria participar de um grupo. Nunca tem".

A dimensão ação social, mesmo que não se efetive plenamente, é considerada desejável pelos sujeitos, embora às vezes fiquem na expectativa de que um terceiro tome iniciativa para implementá-la. Isso é observado nas falas de Beatriz 20, acima, e de Baltazar 23, quando se refere às organizações como desejáveis: "Como na Vila Braz, eles já conversam, já fazem de tudo, mas aqui, aqui não. Se tivesse um clube de tudo, vôlei, futebol, gincana, essas coisas dia de semana, não iria existir tanta coisa [violência] assim".

Chama a atenção o fato de que os entrevistados enfatizam que os mais envolvidos ou responsáveis por situações de violência são os jovens do sexo masculino. Baltazar 23 diz que "a violência aqui é muito forte. Aqui no beco, aqui para cima. Isso a gente tem medo. Aqui mataram um guri [adolescente] amigo meu ... envolvido com drogas ... Se diz assim 'pegar e fazer pela própria mão', ... à base do revólver. Matou pelas próprias mãos e com arma de fogo. Eles não vão mais de mão limpa, vão todos armados, e isso está deixando a vila muito preocupada ... e com medo. Tem gente aí que começa com 6 ou 7 anos já está com uma arma na mão, experimentando droga. E não existe isso: mais de dia ou mais de noite. É qualquer hora. Dá vontade eles vão aí e fazem". Nesse mesmo sentido, Beatriz 20 referiu que: "eu vi aqui na esquina bastante morte. A gente só sai na rua depois que pára. Esses dias um rapaz levou um tiro ali na esquina, uma outra pessoa saiu para ajudar e morreu também. Uns dizem que é tráfico. Tipo, se tem alguma coisa eles pegam, estão vendendo ... de 12 a 17 ou 18 [anos de idade]".

No tocante à segurança pública, houve verbalizações no sentido de impunidade e descaso. Como disse Baltazar 23, "eles falam na gíria 'eu vou matar porque é legal', sabe. No sentido deles acham que é coisa boa. É tudo tranquilo". Beatriz 20 refere que "esses dias uma garota levou uma facada na frente da escola. A gente ligou para a SAMU [Serviço de Atendimento Móvel de Urgência]. A SAMU disse que não ia vir porque era trote".

Berenice 49 reforçou a relação entre violência e drogas dizendo: "aqui, no sentido de violência, a droga é um problema muito sério. Eu me preocupo, porque tu não sabes quando isso vai parar ou até onde vai chegar. Eu ainda acho que a maior violência é a droga, porque a droga leva a tudo. Tem briga, tem morte. Ainda faz uns 4 dias atrás um matou o outro".

\section{DISCUSSÃO}

O presente estudo mostrou que, na Cidade de São Leopoldo, o relato de ocorrência de discussão violenta e homicídios foi cerca de 3 vezes maior nos locais onde as pessoas referiam elementos desfavoráveis, como baixa confiança e menor controle social informal na vizinhança, do que nos locais com características favoráveis. A visão que permeia o presente artigo é a de que o capital social é um bem coletivo, o qual está presente nas estruturas e processos de bairros e vizinhanças. Estudos anteriores sugerem que em zonas onde estão presentes a con- 
fiança entre vizinhos, o apoio social e o controle social informal a contribuição do capital social é maior, com diminuição dos índices de criminalidade $(21,22)$.

Coleman e Putnam $(9,10)$ mostram que a confiança diz respeito aos elos que se estabelecem entre familiares e amigos através de valores comuns, produzindo relações sociais mais cooperativas. Para Putnam $(10,11)$, a confiança tem a ver com as características da organização social, das ações coordenadas e da cooperação espontânea. Através da confiança se desenvolvem as cadeias de relações sociais, as quais dizem respeito também ao bem público. A cooperação se eleva à medida que aumenta a confiança, e consequentemente, parece haver aumento de capital social (20).

Em relação a capital social e violência, Sampson et al. (18) avaliaram a "eficácia coletiva" como a disponibilidade dos residentes locais de intervir para o bem comum e contra a violência em bairros de Chicago, Estados Unidos. Os autores concluíram que altos níveis de eficácia coletiva estavam fortemente relacionados a baixas taxas de violência, mesmo após o controle de características individuais, como estrutura familiar, aspectos socioeconômicos e tempo de moradia na área. Estudos associando capital social medido através de indicadores de confiança interpessoal, cooperação mútua e normas de reciprocidade - com criminalidade mostraram que a potencialização do capital social em estados americanos estava associada com taxas reduzidas de violência $(19,21,22)$. Os resultados do presente estudo mostraram que aspectos importantes para a redução das taxas de violência na área de residência seriam a presença de construtos tais como confiança entre vizinhos, apoio social e controle social informal.

$\mathrm{O}$ perfil das áreas residenciais têm-se modificado nas últimas décadas no Brasil. Nas cidades atuais, as pessoas se cruzam, mas se desconhecem, gerando relações superficiais. Esse viver nas cidades tem implicações na vida das pessoas e nos determinantes sociais que operam através de diversos processos. A urbanização acelerada não propiciou a difusão de práticas sociais de tolerância e civilidade nos espaços urbanos. A ausência da socialização e de negociações tornou a violência uma característica complexa do mundo urbano $(38,39)$.

No que se refere ao envolvimento de adolescentes e jovens entre 15 a 24 anos de idade na violência, o número de homicídios no Brasil passou de 13186 em 1996 para 17312 em 2006, o que significa um aumento de $31,3 \%$ para essa faixa etária (30). Um estudo da mortalidade em adolescentes de 10 a 19 anos no $\mathrm{Mu}$ nicípio do Rio de Janeiro (de 1980 a 1994) mostrou que, do total dos mortos, $74,6 \%$ tinham de 15 a 19 anos e 75,3\% eram do sexo masculino (40). O porte de armas e o uso de drogas pode elevar a violência e está influenciando o perfil de morbidade e mortalidade da população mundial (4) e brasileira $(2,7,30)$.

Quando algumas das pessoas que participaram da pesquisa manifestam sentir-se à margem, no "canto dos esquecidos", referem-se a espaços geográficos que são também demarcações sociais e morais. Nesses contextos, os processos sociais afetam a vida física, mental, social, cultural, econômica e emocional, gerando morte e medo na comunidade (41). As análises sobre violência apontam para sentimentos de medo e insegurança na população urbana em decorrência de crimes violentos $(38,41)$. Por outro lado, as intervenções multissetoriais com atitudes geradoras de capital social são apontadas como inibidoras de atitudes violentas $(42,43)$. Assim, pode-se supor que a ausência de associação entre percepção política e violência referida é um reflexo da desatenção do setor público. É possível pensar nessa ausência de associação como um indicativo de falhas nas políticas públicas sociais e de segurança. Determinadas atitudes do Estado podem decepcionar e afastar o povo da ação e da participação política, gerando desprezo, perplexidade, cansaço, revolta e descrédito.

Segundo Szreter e Woolcock (13), os principais tipos de capital social seriam a tríade bonding, (vínculos), bridging (conexões) e linking (ligações). Os autores destacam que as concepções teóricas de capital social deveriam contemplar a tríade. Os vínculos referem-se aos relacionamentos horizontais próximos entre indivíduos ou grupos com características demográficas similares, relações entre membros da família e amigos próximos. Esses vínculos contribuem para a qualidade de vida através da promoção do apoio e entendimento mútuo. As conexões referem-se a redes mais amplas de relacionamentos com outros indivíduos e comunidades e são vitais para ligar indivíduos e comunidades a recursos ou oportunidades que estão fora das suas redes de relacionamentos pessoais. Por último, as ligações se referem às alianças com indivíduos em posições de poder, particularmente poder sobre recursos necessários para o desenvolvimento social e econômico, podendo ser caracterizadas como percepção política enquanto integração com outras comunidades $(13,14)$. Esses construtos aparecem nas falas dos indivíduos e estão contemplados na mensuração quantitativa do capital social.

Em uma visita ao setor de maior capital social, e através dos dados obtidos nas entrevistas, constatou-se que existe uma infraestrutura que favorece as mais variadas formas de capital social, por exemplo: academia de ginástica na associação, associação de bairro, clube de futebol, clube de mães, escola aberta, escola particular, escola pública, grupo de jovens, igrejas (diversas confissões), local com atividades para crianças mais necessitadas, local com orientação para pais com filhos dependentes químicos, parque com diversas atividades, rádio comunitária, unidades de saúde e empresas com ofertas de emprego. Por outro lado, no setor de menor capital social, tais instituições e oportunidades não foram relatadas. Para que o capital social manifeste seus benefícios, são necessárias infraestrutura e redes sociais que englobem necessariamente o Estado enquanto poder público e a sociedade civil $(19,44)$.

Os resultados encontrados no presente estudo sugerem que quem mais buscava melhorias para seu local de moradia e possuía maior ação social referiu mais violências. O espaço da micropolítica é o espaço comunitário que, através das relações sociais, possibilita o empoderamento dos sujeitos e a construção de redes sociais. Isso indica que quem participa mais tende a ter um grau de empoderamento maior, pois a participação permite um olhar crítico da realidade, um saber pronunciar-se a respeito de questões sociais (44) como, por exemplo, a violência. É possível afirmar, nesse sentido, que o empoderamento seria a primeira condição para que a pessoa se aproprie da importância do viver em sociedade. O sujeito se reconhece pertencente à comunidade, interage com outros sujeitos e favorece a construção da capacidade pessoal voltada para o social. Portanto, exerce um papel ativo voltado ao bem comum, à construção de uma sociedade mais justa e consequentemente à redução da violência (44). 
O comprometimento coletivo seria o fortalecimento dos laços de respeito, tolerância e reconhecimento mútuo entre indivíduos, grupos e setor público. É o rompimento do individualismo. Nesse sentido, o comprometimento dos indivíduos para com a comunidade e o bem comum, através de ações políticas, poderia levar à construção de redes e conexões capazes de transformações sociais e políticas significativas (44).

Neste estudo, os dados qualitativos mostram que os sujeitos se afastam da participação por não perceberem como resolutivas as atuações de serviços públicos. Muito embora o sujeito ainda não mostre uma corresponsabilidade com o bem público, isso não significa que não refira a necessidade da presença atuante da segurança pública e do poder público em prol da comunidade. Segundo Tavares dos Santos (45), as questões de violência e segurança que permeiam a percepção política resultam da ausência de resultados da política de segurança pública no sentido de reduzir a violência. Por conseguinte, os indivíduos estão cada vez mais vulneráveis.

Uma das limitações da abordagem quantitativa é a possibilidades de causalidade reversa. Tanto o capital social poderia reduzir níveis de violência, como a violência poderia reduzir os níveis de capital social. Por exemplo, a baixa confiança entre vizinhos pode ser tanto causa como consequência de um evento violento. Outra limitação é a inexistência de dados sobre envolvimento pessoal com a violência. Isso possibilitaria a realização de análises multivariadas com controle de outras exposições que poderiam influenciar a violência. Assim, para elucidar as associações aqui relatadas, é essencial a realização de estudos longitudinais que possam avaliar o efeito do capital social ao longo do tempo. Além disso, o achado de baixa ação social como proteção para violência também pode ser resultado de confusão residual, ou seja, é possível que os locais com baixa ação social sejam aqueles que apresentam melhores condições socioeconômicas e, portanto, menor violência. Vale ainda ressaltar que os possíveis efeitos negativos relacionados ao capital social, que poderiam favorecer a violência, não foram avaliados no presente estudo, sendo, portanto, necessários novos estudos que abordem essa questão.

Dadas as características da população e a proposta metodológica do estudo, podem ser feitos outros questionamentos: de que forma as organizações e o Estado contribuem para o fortalecimento e a construção do capital social? De que maneira o poder público poderia fomentar a ação social, o exercício da cidadania e o empoderamento dos sujeitos? Quais as melhores intervenções para fomentar capital social e assim reduzir a violência?

Considerando que a violência constitui um conjunto de agravos complexos e está entre as principais causas de morte nas sociedades do mundo moderno, faz diferença ter uma comunidade organizada e participativa com vistas à redução da violência (45). Abordar o problema de maneira intersetorial e interinstitucional (46), organizar grupos já existentes, promover a formação de associações para alcançar metas instrumentais e criar as condições para uma cooperação mais ampla (47) são ações necessárias para essa redução. Essas ações podem contribuir para que os indivíduos tenham a possibilidade de viver com tranquilidade (41), assegurando seus direitos e potencializando sua qualidade de vida.

O capital social é um instrumento básico na qualificação do viver e conviver em sociedade (44). Por englobar construtos que remetem a uma perspectiva interdisciplinar, a utilização do capital social pode contribuir para a promoção de políticas de saúde, para a melhoria da assistência e a redução da violência $(22,48$, 49). O presente estudo corrobora as análises encontradas na literatura, de que a utilização e a operacionalização do conceito de capital social podem contribuir para a promoção do bem comum e para a redução da violência.

Agradecimentos. EAV recebeu bolsa de mestrado do Programa de Suporte à Pós-Graduação de Instituições de Ensino Particulares (PROSUP/CAPES). JRJ e MTAO são bolsistas de produtividade em pesquisa do Conselho Nacional de Desenvolvimento Científico e Tecnológico (CNPq). MPP recebeu apoio financeiro do CNPq (processos 478503/2004-0 e 481410/2009-0) e da Fundação de Amparo à Pesquisa do Rio Grande do Sul (FAPERGS) (processo 0415621).

\section{REFERÊNCIAS}

1. Chesnais JC. Histoire de la violence en Occident de 1800 à nos jours. Paris: Robert Laffont. 1981.

2. Minayo MCS. The inclusion of violence in the health agenda: historical trajectory. Cien Saude Colet. 2006;11(2):375-86.

3. Michaud Y. La violence: une question de normes. Sciences humaines. 1998;89:20-5.

4. Krug EG, Dahlberg LL, Mercy JA, Zwi AB, Lozano R, eds. World report on violence and health. Genebra: WHO. 2002.

5. Organización Panamericana de la Salud. Las condiciones de salud en las Américas. Washington D.C.: OPS; 1994.

6. World Health Organization. Global Consultation on violence and health. Prevention of violence: a public health priority. Genebra: WHO; 1996. Disponível em: www.who.int/ violence_injury_prevention/resources/ publications/en/WHA4925_eng.pdf. Acessado em 14 outubro de 2010.

7. Peres, MFT. Violência por armas de fogo no Brasil - Relatório Nacional. São Paulo: Nú- cleo de Estudos da Violência, Universidade de São Paulo; 2004.

8. Organización Panamericana de la Salud. Indicadores básicos. Washington D.C.: OPS; 1998.

9. Coleman JS. Social capital in the creation of human capital. Am J Sociol; 1988;94:S95-S120.

10. Putnam RD. The prosperous community: social capital and public life. Am Prospect; 1993; 13:35-42.

11. Putnam RD, Leonardi R, Nanetti RY. Making democracy work: civic traditions in modern Italy. Princeton: Princeton University Press; 1993.

12. Woolcock M. Social capital and economic development: toward a theoretical synthesis and policy framework. Theory Soc. 1998;27(2): 151-208.

13. Szreter S, Woolcock M. Health by association? Social capital, social theory, and the political economy of public health. Int J Epidemiol. 2004;33(4):650-67.

14. Pattussi MP, Moysés SJ, Junges JR, Sheiham A. Capital social e a agenda de pesquisa em epi- demiologia. Cad Saude Publica. 2006;22(8): 1525-46.

15. Muntaner C, Lynch J, Smith GD. Social capital and the third way in public health. Critical Public Health; 2000;10(2):107-24.

16. Lynch J, Due P, Muntaner C, Smith GD. Social capital - is it a good investment strategy for public health? J Epidemiol Community Health. 2000;54(6):404-8.

17. Lynch JW, Smith GD, Kaplan GA, House JS. Income inequality and mortality: importance to health of individual income, psychosocial environment, or material conditions. BMJ. 2000;320(7243):1200-4.

18. Sampson RJ, Raudenbush SW, Earls F. Neighborhoods and violent crime: a multilevel study of collective efficacy. Science. 1997;277(5328): 918-24.

19. Kennedy BP, Kawachi I, Prothrow-Stith D, Lochner K, Gupta V. Social capital, income inequality, and firearm violent crime. Soc Sci Med. 1998;47(1):7-17. 
20. Wilkinson RG. Unhealthy societies: The afflictions of inequality. Londres: Routledge; 1996.

21. Wilkinson RG, Kawachi I, Kennedy BP. Mortality, the social environment, crime and violence. Sociol Health Illn. 1998;20(5):578-97.

22. Kawachi I, Kennedy BP, Wilkinson RG. Crime: social disorganization and relative deprivation. Soc Sci Med. 1999;48(6):719-31.

23. Galea S, Karpati A, Kennedy BP. Social capital and violence in the United States, 1974-1993. Soc Sci Med. 2002;55(8):1373-83.

24. Rubin HJ, Rubin IS. Qualitative interviewing: The art of hearing data. London: Sage Publications; 1995.

25. Briceño-Leon R. Quatro modelos de integração de técnicas qualitativas e quantitativas de investigação nas ciências sociais. Em: Goldberg P, Marsiglia RMG, Gomes MHA, orgs. O clássico e o novo: tendências, objetos e abordagens em ciências sociais e saúde. Rio de Janeiro: Fiocruz; 2003. Pp 157-83.

26. Denzin NK. The Research Act. Chicago: Aldine Publishing Company; 1973.

27. Minayo MCS. Introdução: conceito de avaliação por triangulação de métodos. Em: Minayo MCS, Assis SG, Souza RE, orgs. Avaliação por triangulação de métodos: abordagens de programas sociais. Rio de Janeiro: Fiocruz; 2005. Pp 19-51.

28. Prefeitura de São Leopoldo. Dados socioeconômicos. Disponível em: <www.sao leopoldo.rs.gov.br/home/show_page.asp? id_CONTEUDO $=1372 \&$ codID_CAT $=21 \&$ id_SERVICO $=\&$ categoria $=\langle\mathrm{b}\rangle$ Cidade $</ \mathrm{b}\rangle$. Acessado em 14 outubro de 2010.

29. Instituto Brasileiro de Geografia e Estatística. Censo Demográfico 2000 - resultados do universo: agregados dos setores censitários. v. 9. Rio Grande do Sul [CD-ROM]. Rio de Janeiro: IBGE; 2000

30. Waiselfisz JJ; Rede de Informação Tecnológica Latino-Americana, RITLA; Instituto Sangari; Ministério da Saúde; Ministério da Justiça.
Mapa da violência dos municípios brasileiros 2008. Brasília: Ideal Gráfica e Editora; 2008.

31. Governo do Estado do Rio Grande do Sul, Secretaria Estadual da Saúde, Centro Estadual de Vigilância em Saúde. Notificação compulsória de casos suspeitos ou confirmados de violência. Porto Alegre: CEVS/RS; 2007.

32. Stafford M, Bartley M, Mitchell R, Marmot M. Characteristics of individuals and characteristics of areas: investigating their influence on health in the Whitehall II study. Health Place. 2001;7(2):117-29.

33. Muntaner C, Oates GL, Lynch JW. Social class and social cohesion: a content validity analysis using a nonrecursive structural equation model. Ann N Y Acad Sci. 1999;896:409-13.

34. Baum FE, Bush RA, Modra CC, Murray CJ, Cox EM, Alexander KM et al. Epidemiology of participation: an Australian community study. J Epidemiol Community Health. 2000; 54(6):414-23.

35. Barros AJ, Hirakata VN. Alternatives for logistic regression in cross-sectional studies: an empirical comparison of models that directly estimate the prevalence ratio. BMC Med Res Methodol. 2003;3:21.

36. Bardin L. Análise de conteúdo. Lisboa: Persona 1977.

37. Minayo MCS, org. O desafio do conhecimento: pesquisa qualitativa em saúde. $8^{\mathrm{a}}$ ed. São Paulo — Rio de Janeiro: Hucitec-Abrasc; 2004.

38. Zaluar A. Noronha J. Albuquerque C. Violência: pobreza ou fraqueza institucional? Cad Saude Publica. 1994;10(1 supl):213-7.

39. Vial EA, Asquidamini F, Junges JR. Vulnerabilidades socioeconômicas e violência no contexto juvenil. Em: Asquidamini F, Vial EA, orgs. Sustentabilidade eis a questão: juventudes, trabalho e economia. São Leopoldo: ConTexto Gráfica; 2010. Pp 31-42.

40. Souza ER, Assis SG, Silva CMFP. Violência no Município do Rio de Janeiro: áreas de risco e tendências da mortalidade entre adolescentes de 10 a 19 anos. Rev Panam Salud Publica. 1997;1(5):389-98

41. Cardia N. Pesquisa sobre atitudes, normas culturais e valores em relação à violência em dez capitais brasileiras. Relatório de pesquisa. Brasília: Ministério da Justiça, Secretaria Nacional de Direitos Humanos; 1999.

42. Vlahov D, Freudenberg N, Proietti F, Ompad D, Quinn A, Nandi V, Galea S. Urban as a determinant of health. J Urban Health. 2007;84 (1 Suppl): 16-26.

43. Caiaffa WT, Ferreira FR, Ferreira AD, Oliveira CL, Camargos VP, Proietti FA. Saúde urbana: "a cidade é uma estranha senhora, que hoje sorri e amanhã te devora". Cien Saude Colet. 2008;13(6):1785-96.

44. Gohn MG. O protagonismo da sociedade civil: Movimentos sociais, ONGS e redes solidárias. São Paulo: Cortez; 2005.

45. Tavares dos Santos JV. Violências e dilemas do controle social nas sociedades da "modernidade tardia". São Paulo Perspec. 2004;18(1):3-12.

46. Agudelo SF. Violencia y salud en Colombia Rev Panam Salud Publica. 1997;1(2):93-103.

47. Baquero M. Construindo uma outra sociedade: o capital social na estruturação de uma cultura política participativa no Brasil. Rev Sociol Polit. 2003;21:83-108.

48. Kawachi I, Berkman LF. Neighborhoods and health. New York: Oxford University Press; 2003.

49. Pattussi MP, Junges JR, Selli L, Moysés SJ. A influência do capital social no contexto da estratégia saúde da família. Em: Moysés ST, Kriger L, Moysés SJ, orgs. Saúde bucal das famílias - trabalhando com evidências. São Paulo: Artes Médicas; 2008. Pp 207-15.

Manuscrito recebido em 6 de novembro de 2009. Aceito em versão revisada em 10 de junho de 2010.

ABSTRACT Objective. To study the relationship between reported urban violence and social capital in a medium-sized city in the state of Rio Grande do Sul, Brazil.

Urban violence and social capital in a southern Brazilian city: a quantitative and qualitative study

Methods. The study was carried out with adults living in the urban area of São Leopoldo. For the quantitative analysis, a structured questionnaire was answered by 1100 individuals older than 20 years of age and in charge of the household at the moment of the interview. Violence was evaluated based on the reports of violent arguments, theft or robbery, drug-related events, and homicides in the neighborhood over the previous six months. Social capital was defined based on the reported degree of trust among neighbors, informal social control, opinions on the actions of government and politicians, and social action in the neighborhoods. For the qualitative analysis, 11 participants residing in the area with the lowest or with the highest social capital answered a semi-structured interview.

Results. People living in low-trust neighborhoods reported higher rates of homicide $(\mathrm{OR}=2.82 ; 95 \% \mathrm{CI}: 1.67-4.74 ; P>0.001)$ and violent arguments $(\mathrm{OR}=2.56 ; 95 \% \mathrm{CI}$ : 1.82-3.59; $P>0.001)$ than people living in high-trust neighborhoods. Violent situations were reported most often in neighborhoods with low social capital, in which a lack of government attention was also reported.

Conclusions. In neighborhoods with the highest social capital, the prevalence of reported violence was lower. Priority should be given to public policies that promote social capital for the common good.

Key words Violence; qualitative research; cross-sectional studies; social medicine; Brazil. 